\title{
КОНСТИТУЦИОННО-ПРАВОВЫЕ ОСНОВЫ РЕАЛИЗАЦИИ НАСЕЛЕНИЕМ ПРАВ ГРАЖДАН В СФЕРЕ ТЕРРИТОРИАЛЬНОГО УСТРОЙСТВА СУБЪЕКТА РОССИЙСКОЙ ФЕДЕРАЦИИ
}

\begin{abstract}
Аннотация: Наряду с изменениями территориальной основы местного самоуправления в субъектах Российской Федерации на практике появляется необходимость внесения изменений в административно-территориальное устройство. Реализация этой потребности требует соотнести полномочия государственных органов субъектов самостоятельно решать вопросы административно-территориального устройства и императивные требования законодательства о местном самоуправлении. В статье акцентируется определенная «автономность» процессов изменения административно-территориального устройства, в тех случаях, когда административно-территориальная единица включает территорию нескольких муниципальных образований.Одной из важнейших проблем развивающейся российской государственности является преодоление отчуждения гражданина от государства. Рассматриваются вопросы регламентации в законах субъектов Российской Федерации об административно-территориальном устройстве процедур учета мнения населения при изменении административно-территориального устройства.По результатам анализа отмечается, что такая регламентация характеризуется недостаточной унифицированностью и непроработанностью как в содержательном, так и юридико-техническом отношении и требует расширения. Именно это актуализирует включение федерального законодателя в процесс правового регулирования административно-территориального устройства субъектов Федерации.

Review: Along with the changes in the territorial basis for the municipal self-government in the constituent subjects of the Russian Federation, there appears a practical need to change administrative territorial structure. Its implementation calls for establishing correlation of the powers of the state bodies of the constituent subjects to make independent decisions on it administrative and territorial structure and the imperative requirements of the legislation on municipal self-government. It is pointed out in the article that there's certain autonomy in the process of changing administrative and territorial structure, when an administrative territorial unit includes territory of several municipal units. One of the most important challenges for the developing Russian statehood is to overcome alienation between a citizen and the state. The author evaluates the issues of regulations on administrative territorial structure of the constituent subjects of the Russian Federation and the procedures of evaluation of the public opinion on the changes in administrative and territorial structure. Based on the results of the analysis, the author notes that the regulations are not sufficiently uniform and they have weak conceptual framework, both in their contents and legal technique, requiring broadening. This matter makes involvement of the federal legislator into the process of legal regulation of the administrative and territorial structure of the constituent subjects of the Russian Federation so topical.
\end{abstract}

Ключевые слова: административно-территориальное устройство, субъекты Российской Федерации, императивный референдум, консультативный референдум, публичные слушания, конференции, собрания, сходы, права человека, местное самоуправление

Keywords: administrative and territorial structure, constituent subjects of the Russian Federation, imperative referendum, consultative referendum, public hearings, conferences, meetings, gatherings, human rights, municipal self-government.

$\mathbf{X}$ арактерной чертой территориального устройства субъектов Российской Федерации является определенный дуализм, когда: во-первых, территория субъекта разделена на административно-территориальные единицы; во-вторых, на всей территории субъекта функционирует местное самоуправление, которое осуществляется в границах муниципальных образований разных типов. Территориальное устройство государства традиционно включала в себя в качестве первичного элемента административно-территориаль- ные единицы, но в связи с признанием местного самоуправления в качестве одной из основ конституционного строя дополнилась территориальными единицами особого рода, где осуществляются не только функции административного управления, но и задачи политической и социально-экономической самоорганизации населения. На территориях муниципальных образований формируется и функционирует такой специфический институт, как местное сообщество, которое является истинным субъектом самоуправления. 
В 1989 году при обсуждении концепции будущего Закона СССР о местном самоуправлении и местном хозяйстве Краснов М.А. отмечал, что «местное самоуправление, понимаемое как самостоятельное решение местных вопросов самим населением, объединяемым соответствующим Советом, реализация принятых решений, предполагает организационную упорядоченность не только Совета, но и населения, т. е. последнее должно быть представлено в виде территориального коллектива. Это пока задача на будущее. Но ее постановка в законе необходима, ибо без нее не приходится говорить о возможности реального самоуправления. Уровень местного самоуправления, помимо всего прочего, прямо пропорционален степени консолидации населения. Итак, одна из задач на сегодня образование коммун как ячеек всеобщего самоуправления в масштабах страны» ${ }^{1}$. Прошло почти четверть века, а поставленная задача, пусть уже не в такой «романтической» постановке, все еще на повестке дня. Территориальная организация населения - это пространственная основа участия граждан в осуществлении народовластия. Население городского или сельского поселения, которое осознает общность своих интересов и участвует прямо или через своих представителей в решении местных проблем, по существу функционирует как местное сообщество.

Конституцией Российской Федерации установлено, что изменение границ территорий, в которых осуществляется местное самоуправление, допускается с учетом мнения населения соответствующих территорий (ч. 2 ст. 131). В Европейской хартии местного самоуправления ${ }^{2}$ в ст. 5, которая называется «Защита границ территорий, в которых осуществляется местное самоуправление», установлено, что «при любом изменении местных территориальных разграничений необходимо предварительно консультироваться с соответствующими органами местного самоуправления, возможно, там, где это позволяет закон, путем проведения референдума». Таким образом, статья содержит требование к национальному законодательству относительно изменения границ территорий местного самоуправления. Изменение границ допускается только с учетом мнения населения соответствующих территорий, в том числе путем проведения референдума там, где это допускается законом. В части 2 статьи 3 Хартии установлено, что осуществление местного самоуправления представительными органами и собраниями «не исключает обращения к собраниям граждан, референдуму или любой другой форме прямого участия граждан там, где это допускается

\footnotetext{
${ }^{1}$ Краснов М.А. К разработке проекта закона о местном самоуправлении и местном хозяйстве // Сов.государство и право. 1989. № 2. C. 87.

${ }^{2}$ Федеральный закон от 11.04.1998 № 55-Ф3 «О ратификации Европейской хартии местного самоуправления» // Собрание законодательства Российской Федерации. 1998. № 15. Ст. 1695.
}

по закону». То есть, возможно использовать любые другие формы прямого участия граждан, если это допускается законом. Оговорка в Европейской хартии местного самоуправления относительно закона чрезвычайно важна, поскольку обращение к таким формам принятия решения, как собрания граждан и референдум, возможно только в том случае, если закон позволяет сделать это

Федеральный закон «Об общих принципах организации местного самоуправления в Российской Федерации» от 28.08.1995 $5^{4}$ устанавливал, что «вопросы об образовании, объединении, о преобразовании или об упразднении внутригородских муниципальных образований, установлении или изменении их территорий решаются с учетом мнения населения соответствующей территории представительным органом местного самоуправления города самостоятельно в соответствии с уставом города» (ч. 3 ст. 12). Таким образом, представительный орган местного самоуправления города, принимая решения о статусе внутригородских муниципальных образований, обязан был учитывать мнение населения. В комментариях Института законодательства и сравнительного правоведения при Правительстве Российской Федерации к этому положению закона читаем: «это мнение может быть выявлено в результате опросов населения, а также выражаться в решениях и рекомендациях собраний по месту жительства, актах народной правотворческой инициативы, обращениях граждан в органы местного самоуправления и т.п. Обязанность учитывать мнение населения предполагает публичное рассмотрение поступивших предложений представительным органом местного самоуправления города с приглашением представителей сторон, выражающих различные точки зрения» ${ }^{5}$ Комментарий допускал, что представительный орган местного самоуправления города может принять решение вопреки мнению населения, только оно должно быть мотивированным. А гарантии учета мнения населения внутригородских образований в случае изменения границ этих территорий должны были устанавливаться законами соответствующего субъекта Российской Федерации.

\footnotetext{
${ }^{3}$ Дементьев, А.Н. Правовые гарантии учета мнения населения при изменении границ муниципальных образований // Государственная власть и местное самоуправление. 2005. № 10. С.9.

${ }^{4}$ Федеральный закон от 28.08.1995 № 154-Ф3 (ред. от 21.07.2005) «Об общих принципах организации местного самоуправления в Российской Федерации» //Собрание законодательства Российской Федерации, 28.08.1995, № 35, ст. 3506.Документ утратил силу с 01.01.2009 в связи с принятием Федерального закона от 06.10.2003 № 131-Ф3.

${ }^{5}$ Комментарий к Федеральному закону «Об общих принципах организации местного самоуправления в Российской Федерации». Руководитель авторского коллектива и ответственный редактор - доктор юридических наук, профессор Ю.А. Тихомиров. - М., 1997. C. 58.
} 
DOI: $10.7256 / 1811-9018.2013 .8 .9292$

При цитировании этой статьи сноска на dоі обязательна

\section{Право и политика $8(164) \cdot 2013$}

В части 2 статьи 13 закон устанавливал, что «изменение границ муниципального образования не допускается без учета мнения населения соответствующих территорий. Законодательные (представительные) органы государственной власти субъектов Российской Федерации устанавливают законом гарантии учета мнения населения при решении вопросов изменения границ территорий, в которых осуществляется местное самоуправление». Субъектами инициативы об установлении и изменении границ муниципального образования могли выступать: население муниципального образования, органы местного самоуправления муниципального образования, а также органы государственной власти соответствующего субъекта Российской Федерации. Закон не определял орган, полномочный принять решение об установлении и изменении границ муниципального образования. Этот вопрос решался субъектами Российской Федерации самостоятельно. В указанных комментариях к закону этих положений дается разъяснение, что обязательный учет мнения населения при изменении границ муниципального образования должен обеспечиваться путем определения в законах субъектов Российской Федерации конкретных форм этого учета и степени его императивности.

Конституционный Суд Российской Федерации в постановлении от 24.01.1997 № 1-П по делу о проверке конституционности положений Закона Удмуртской Республики от 17.04.1996 «О системе органов государственной власти в Удмуртской Республике» ${ }^{6}$ установил, что наиболее адекватной формой учета мнения населения при изменении границ территорий, в которых осуществляется местное самоуправление, является референдум. В ряде субъектов Российской Федерации, таких как Республика Адыгея, Приморский, Хабаровский края, Сахалинская, Ярославская области, Ханты-Мансийский автономный округ, были предусмотрены такие формы решения вопросов изменения территорий муниципалитетов, как местный референдум и сход граждан. А в таких субъектах Российской Федерации как Республики Алтай, Мордовия, Воронежская, Читинская области, в дополнение к референдумам и сходам граждан учет мнения населения предполагалось проводить в таких формах, как опрос населения, конференция жителей, общее собрание граждан. Например, согласно статье 14 Закона Омской области «О местном самоуправлении в Омской области» границы территорий, в которых осуществляется местное самоуправление, не могут быть изменены без учета мнения

${ }^{6}$ Постановление Конституционного Суда Российской Федерации от 24.01.1997 № 1-П по делу о проверке конституционности положений Закона Удмуртской Республики от 17.04.1996 «О системе органов государственной власти в Удмуртской Республике» // Собрание законодательства Российской Федерации. 1997. № 5. Ст. 708. населения соответствующей территории, выраженного на референдуме, сходе или конференции граждан в порядке, установленном уставом (положением) о местном самоуправлении. Границы территорий местного самоуправления не могут быть изменены, если против этого высказались 50 или более процентов граждан, принявших участие в референдуме, сходе или конференции, проводимых с целью выяснить мнение населения соответствующей территории по данному вопросу7.

Во многих субъектах Российской Федерации решение вопросов изменения границ муниципальных образований увязывалось с решением вопросов административно-территориального устройства. Практика проведения местных референдумов по решению вопросов изменения границ муниципальных образований в субъектах Российской Федерации немногочисленна. В большинстве случаев проведение местного референдума обусловливалось наличием инициативы граждан. В комментариях к закону отмечалось, что ряд существенных вопросов, связанных с территориальной организацией местного самоуправления, решается в законах субъектов Российской Федерации о территориальном или административно-территориальном устройстве. Сложность вопросов, возникающих в этой сфере, правовые проблемы, с которыми сталкиваются субъекты Российской Федерации в ходе нормативного регулирования порядка образования, объединения или упразднения муниципальных образований, порождают необходимость участия федерального законодателя в их решении. Наиболее оптимальной формой воздействия Федерации на территориальное устройство субъектов являются модельные законы. В комментариях приводятся основные положения структуры проекта модельного закона Института законодательства и сравнительного правоведения о территориальном устройстве субъекта Российской Федерации. В проекте совмещаются нормы, регулирующие административно-территориальное устройство субъекта, и нормы, регулирующие территориальную основу местного самоуправления ${ }^{8}$.

Федеральный закон «Об общих принципах организации местного самоуправления в Российской Федерации» 2003 года содержит такую важную новеллу как согласие населения на изменение границ или преобразование муниципального образования. В одних случаях, такое согласие население может выразить непосредственным голосованием, в других - опосредованно, кода согласие населения выражается представительным органом местного самоуправления.

Законом установлены случаи, когда согласие населения, выраженное голосованием, является обязательным:

\footnotetext{
${ }^{7}$ См.: Тихомиров Ю.А. Указ.изд. С. 60.

${ }^{8}$ Там же. С. 61
} 
а) изменение границ муниципальных районов, влекущее отнесение территорий отдельных входящих в их состав поселений и (или) населенных пунктов к территориям других муниципальных районов осуществляется с согласия населения данных поселений и (или) населенных пунктов, выраженного путем голосования, с учетом мнения представительных органов соответствующих муниципальных районов;

б) изменение границ поселений, влекущее отнесение территорий отдельных входящих в их состав населенных пунктов к территориям других поселений осуществляется с согласия населения данных населенных пунктов, выраженного путем голосования с учетом мнения представительных органов соответствующих поселений;

в) разделение поселения, влекущее образование двух и более поселений, осуществляется с согласия населения каждого из образуемых поселений, выраженного путем голосования;

г) изменение статуса городского поселения в связи с наделением его статусом городского округа либо лишением его статуса городского округа осуществляется законом субъекта Российской Федерации с согласия населения соответствующего городского поселения, а также с согласия населения муниципального района, из состава которого выделяется (в состав которого включается) соответствующее городское поселение. Мнение населения городского поселения и мнение населения муниципального района выявляются путем голосования. Изменение статуса городского поселения не допускается при отсутствии согласия на такое изменение населения городского поселения и (или) населения муниципального района;

д) инициатива населения об упразднении поселения оформляется решением об упразднении поселения, принятым на сходе граждан, проживающих в указанном поселении;

е) в случае выдвижения на сходе граждан, проживающих в населенном пункте, расположенном на межселенной территории, инициативы о создании вновь образованного поселения такая инициатива оформляется решением схода граждан, проживающих в соответствующем населенном пункте.

Во всех иных случаях согласие населения выражается представительным органом. Голосование по вопросам изменения границ и преобразования муниципального образования являются формой определяющего, решающего, властного участия населения в реализации местного самоуправления. Такая форма прямого волеизъявления сходна с процедурой проведения местного референдума, однако нельзя согласиться с предложением переименовать «голосование»в «референдум»9.

${ }^{9}$ См.: Комарова В.B. Референдум и сходные формы непосредственного народовластия (соотношение и проблемы)// Конституционное
А.Н. Дементьев считает, что применение института местного референдума для выявления мнения населения по вопросу изменения границ и преобразованию муниципального образования невозможно и аргументирует это утверждение тем, что «при изменении границ муниципальных образований всегда затрагиваются интересы по крайней мере не менее двух муниципальных образований. В случае принятия противоположных решений в этих муниципальных образованиях либо в случае, если в одном муниципальном образовании референдум не состоялся, обеспечить общеобязательный статус решения референдума не представляется возможным. На территории одного из муниципальных образований решение референдума в такой ситуации не может быть реализовано. Только консолидированное одинаковое решение референдумов в муниципальных образованиях, границы которых предполагается изменить, предоставляет возможность реализовать решение каждого из них...исходя из совокупного толкования норм Федерального закона от 6 октября 2003 г. № 131-Ф3, референдум может проводиться только на всей территории муниципального образования» ${ }^{10}$.

Голосование по вопросам изменения границ и преобразования муниципального образования нельзя также считать консультативным референдумом ${ }^{11}$, основываясь на том, что окончательное решение по итогам голосования принимает законодательный (представительный) орган государственной власти субъекта Российской Федерации, так как федеральным законодательством установлен только императивный референдум. Указанное голосование в отличие от референдума может проходить и на части территории муниципального образования. С инициативой о проведении голосования могут выступать, помимо населения и органов местного самоуправления, органы государственной власти субъекта Российской Федерации и федеральные органы государственной власти. Процедура проведения голосования не предусматривает запрет на проведение агитации государственными органами, органами местного самоуправления, лицами, замещающими государственные или муниципальные должности. Отсутствует и такой признак как императивность принимаемого решения, поскольку окончательное решение принимается органами государственной власти.

Реализация конституционной модели местного самоуправления требует развития институтов муниципальной демократии, которые, как пишет Н.С. Бондарь,

и муниципальное право. 2005.№9. //Доступ из СПС «Консультант Плюс».

${ }^{10}$ См.: Дементьев А.Н. Указ.соч. С.10.

${ }^{11}$ См.: Авакьян С.А. Институты непосредственной демократии / Конституционные и законодательные основы местного самоуправления в России. М., 2004. С. 238-239; Комарова В.В. Указ. соч. // Доступ из СПС «Консультант Плюс». 


\section{Право и политика $8(164) \cdot 2013$}

«представляют собой весьма специфичную, муниципально-правовую, форму реализации универсального принципа демократической государственности (ч. 1 ст. 1 Конституции) на местном, поселенческом уровне человеческой жизнедеятельности» ${ }^{12}$. Императивность положений закона о проведении голосования населения в случаях, четко оговоренных в законе, требует их неукоснительной реализации, что и происходит в техсубъектах, где возникает потребность в изменении границ и статуса муниципальных образований. Например, избирательная комиссия Нижегородской области сообщает, что в Нижегородской области 662 муниципальных образования, в том числе 48 муниципальных районов, 4 городских округа, 78 городских и 523 сельских поселения. По инициативе органов местного самоуправления 09.08.2009 в 34 районах области проводилось голосование по вопросам преобразования муниципальных образований. В 257 сельских и городских поселениях области их жители высказывались «за» или «против» объединения. В 245 муниципальных образованиях голосование прошло успешно, и согласие населения получено. Таким образом, после принятия Закона области о преобразовании, учитывающего результаты голосования, вместо 216 ныне существующих поселений будет образовано $96^{13}$.

Помимо изменений территориальной основы местного самоуправления в субъектах Федерации появляется необходимость внесения изменений в административнотерриториальное устройство. Реализация этой потребности требует соотнести полномочия государственных органов субъектов самостоятельно решать вопросы административно-территориального устройства и императивные требования Федерального закона «Об общих принципах организации местного самоуправления в Российской Федерации» № 131-Ф3 о необходимости учета мнения населения при изменении границ и преобразовании муниципальных образований. В законах субъектов Российской Федерации об административно-территориальном устройстве содержатся отдельные главы, статьи регулирующие процедуру внесения изменений в административно-территориальное устройство и связанную с этим проблему учета мнения населения.

В законах некоторых субъектов Федерации об административно-территориальном устройстве, на наш взгляд, недопустимо смешиваются такие объекты регулирования как изменение административно-территориального устройства и преобразование муници-

${ }^{12}$ Бондарь Н.С. Местное самоуправление и конституционное правосудие: конституционализация муниципальной демократии в России. М.: НОРМА, 2009. С.6.

${ }^{13}$ См.: Процесс. Оптимизация или контрреформа? // Муниципальное право. № 3, 2009. С. 26. пальных образований. Например, части 5 и 6 статьи 15 Закона Амурской области «О порядке решения вопросов административно-территориального устройства Амурской области» ${ }^{14}$ содержат следующие положения: «В соответствии с Федеральным законом «Об общих принципах организации местного самоуправления в Российской Федерации» изменение статуса городского поселения в связи с наделением его статусом городского округа либо лишением его статуса городского округа осуществляется законом области с согласия населения соответствующего городского поселения, а также с согласия населения муниципального района, из состава которого выделяется (в состав которого включается) соответствующее городское поселение.

Мнение населения городского поселения и мнение населения муниципального района выявляются путем голосования на местном референдуме, проводимом раздельно на территории городского поселения и на территории муниципального района, из состава которого выделяется (в состав которого включается) городское поселение.

Изменение статуса городского поселения не допускается при отсутствии согласия на такое изменение населения городского поселения и (или) населения муниципального района.

В соответствии с Федеральным законом «Об общих принципах организации местного самоуправления в Российской Федерации» изменение границ муниципальных районов и поселений, не влекущее отнесение территорий отдельных входящих в их состав поселений и (или) населенных пунктов соответственно к территориям других муниципальных районов или поселений, осуществляется с учетом мнения населения, выраженного представительными органами соответствующих муниципальных районов и поселений, а объединение двух и более муниципальных районов, не влекущее изменение границ иных муниципальных образований, разделение муниципального района осуществляются с учетом мнения населения, выраженного представительными органами соответствующих муниципальных районов». То же в Законе Республики Калмыкия «Об административно-территориальном устройстве Республики Калмыкия» глава IV «Порядок решения вопросов административно-территориального устройства» содержит статью 11 «Порядок преобразований муниципальных образований» ${ }^{15}$.

\footnotetext{
14 Закон Амурской области от 23.12.2005 № 127-О3 «О порядке решения вопросов административно-территориального устройства Амурской области» (ред. от 26.06.2009) // «Амурская правда», № 11, 24.01.2006.

15 Закон Республики Калмыкия от 06.11.2001 № 138-ІІ-3 «Об административно-территориальном устройстве Республики Калмыкия» (ред. от 27.09.2010) // «Известия Калмыкии», № 255, 27.11.2001.
} 
В законах субъектов Федерации, регулирующих вопросы административно-территориального устройства, должны содержаться четкие положения о том, что, если границы административно-территориальных единиц совпадают с границами муниципальных образований, то изменение границ муниципальных образований одновременно влечет соответствующие изменения административно-территориального устройства. Соответствующее положение содержится, например, в законе об административно-территориальном устройстве Нижегородской области ${ }^{16}$. Практику такого регулирования необходимо распространить во всех субъектах Российской Федерации.

В Определении Верховного Суда Российской Федерации от 05.02.2002 говорится, что статья 4 Закона Красноярского края «закрепляя положение о том, что границы территорий административно-территориальных единиц и муниципальных образований совпадают, указывает, что при изменении границ муниципальных образований должно быть изменено административно-территориальное устройство края. Таким образом, данная норма вводит приоритет изменения границ муниципальных образований, на которых осуществляется местное самоуправление, по отношению к административно-территориальному делению Красноярского края» ${ }^{17}$.

Одновременно нельзя не учитывать определенную «автономность» процессов изменения административно-территориального устройства, в тех случаях, когда административно-территориальная единица включает территорию нескольких муниципальных образований, например, округа в Свердловской области или в границах муниципальных образований существуют административно-территориальные единицы, например, внутригородские районы, сельские округа, волости.

Изменение административно-территориального устройства может осуществляться в следующих формах:

1) перенесение административного центра административно-территориальной единицы;

2) образование населенного пункта;

3) изменение категории и вида населенного пункта;

4) изменение статуса административно-территориальной единицы;

5) изменение границы населенного пункта;

6) объединение, выделение, разделение населенных пунктов;

${ }^{16}$ См.: Часть 2 статьи 14 Закона Нижегородской области от 16.11.2005 №184-3 «Об административно-территориальном устройстве Нижегородской области» (ред. от 04.06.2013) //«Правовая среда», № 94-95(660-661).

${ }^{17}$ См.: Определение Верховного Суда Российской Федерации от 05.02.2002№ 53-Г01-1.
7) упразднение населенного пункта, в котором не проживает население;

8) присвоение наименования и переименование административно-территориальной единицы, населенного пункта;

9) изменение границ административно-территориальных единиц;

10) преобразование административно-территориальных единиц.

В Законе «Об административно-территориальном устройстве Московской области» установлено, что образование, объединение, преобразование и упразднение административно-территориальных единиц, а также установление и перенос административных центров районов производятся законом Московской области по представлению Губернатора Московской области, а образование, объединение, преобразование и упразднение территориальных единиц производятся постановлением Губернатора Московской области (ст. 8). С инициативой образования, объединения, преобразования и упразднения административно-территориальных и территориальных единиц, установления и переноса административных центров районов могут выступать органы местного самоуправления. В перечне документов, которые главы муниципальных образований представляют Губернатору Московской области, указываются «постановление главы и решение Совета депутатов муниципального района, городского округа (для административно-территориальных единиц) либо постановление главы и решение Совета депутатов городского округа, постановление главы муниципального района, а также постановление главы и решение Совета депутатов городского, сельского поселения (для территориальных единиц». Можно предположить, что в этом случае мнение населения выражено представительными органами соответствующих муниципальных образований. В Определении Конституционного Суда от 15.05.2007 говорится, что «Закон Московской области «Об административно-территориальном устройстве Московской области», как следует из его статьи 1 , направлен на регулирование административно-территориального устройства Московской области, порядка решения вопросов административно-территориального устройства и компетенции в данной сфере органов государственной власти Московской области и органов местного самоуправления муниципальных образований Московской области.

В соответствии с подпунктом «а» пункта 1 и подпунктом «а» пункта 2 статьи 6 и статьей 8 данного Закона Московской области образование, объединение, преобразование и упразднение административно-территориальных единиц Московской области осуществляется законом Московской области, а образование, объединение, преобразование и упразднение территориальных единиц 


\section{Право и политика $8(164) \cdot 2013$}

- постановлением Губернатора Московской области. При этом, поскольку территориальная организация местного самоуправления в Московской области (на момент принятия решений об объединении с другими населенными пунктами территорий, на которых проживают заявители) основывалась на административно-территориальном делении Московской области (пункт 1 статьи 68 Устава Московской области в редакции, действовавшей до вступления в силу Закона Московской области от 22.07.2005 № 192/2005-О3, пункт 1 статьи 10 Закона Московской области «Оместном самоуправлении в Московской области», утратившего силу с 01.01.2006), законодатель Московской области в целях гарантирования права граждан на местное самоуправление установил, что изменение статуса территориальных единиц путем принятия решения Губернатора Московской области возможно только по инициативе органов местного самоуправления, действующих в пределах соответствующей территориальной единицы. Это прямо следует из взаимосвязанных положений абзацев первого, второго и третьего пункта 1 раздела I и абзацев первого и второго раздела V приложения к Закону Московской области «Об административно-территориальном устройстве Московской области» ${ }^{18}$.

Необходимость учета мнения населения соответствующих территорий, наряду с учетом государственных интересов, устанавливается в процедуре присвоения наименований и переименование административно-территориальных и территориальных единиц Московской области (ч. 1 ст. 9), однако форма такого учета не оговаривается. В этом случае эффективной мерой было бы предусмотреть в законе такие рекомендательные, консультативные формы выявления мнения населения как опрос, публичные слушания, конференции, собрания.

В ряде законов субъектов Федерации указываются определенные формы учета мнения населения по вопросам административно-территориального устройства. Например, в Законе Республики Мордовия при перечислении документов необходимых для рассмотрения вопросов об образовании, объединении, преобразовании или упразднении административно-территориальных единиц и населенных пунктов, установлении или изменении границ административно-территориальных единиц, определении или перенесении административных центров, наряду с другими документами, необходимо представить протоколы сходов граждан по месту их жительства или протоколы голосования по рассматриваемому вопросу решения соответствующих представительных органов местного самоуправления (ст. 19).

${ }^{18}$ Определение Конституционного Суда Российской Федерации от 15.05.2007 № 406-О-П.
Для рассмотрения вопросов об отнесении населенного пункта к другой категории населенных пунктов (категории города республиканского значения, города районного значения, рабочего поселка, сельского населенного пункта), наряду с другими документами, необходимо представить протокол голосования по рассматриваемому вопросу и решения соответствующих представительных органов местного самоуправления (ст. 20).

Для рассмотрения вопросов о включении населенных пунктов в состав города, рабочего поселка, сельского населенного пункта, а также об изменении черты города, рабочего поселка, сельского населенного пункта, наряду с другими документами, представляются протокол схода граждан или протокол голосования по рассматриваемому вопросу и решения соответствующих представительных органов местного самоуправления (ст. 22) $)^{19}$.

В Законе Республики Алтай установлено, что изменение административно-территориального устройства по вопросам, предусмотренным в законе, «осуществляется законами Республики Алтай по представлению Главы Республики Алтай, Председателя Правительства Республики Алтай на основании решений представительных органов соответствующих муниципальных образований с учетом мнения населения соответствующих территорий, за исключением изменения административно-территориального устройства в форме упразднения населенного пункта, в котором не проживает население» (ст. 9).В перечне документов, представляемых в законодательный орган Республики, называется документ подтверждающий учет мнения населения, проживающего: в административно-территориальной единице (ст. 10); на территории образуемого населенного пункта (ст. 11); в населенном пункте (ст. 12); в объединяемых населенных пунктах (ст. 14); в населенном пункте, из которого образуется один или несколько новых населенных пунктов (ст. 15) ${ }^{20}$ и т.д.

В законе Республики Дагестан статья 9 устанавливает полномочия органов местного самоуправления по вопросам административно-территориального устройства, которые подготавливают проекты решений и вносят предложения в Правительство Республики Дагестан по вопросам образования, объединения, разъединения,

\footnotetext{
${ }^{19}$ См.: Закон Республики Мордовия от23.03.1998 №7-3 (ред. от 19.06.2013) «О порядке решения вопросов административнотерриториального устройства Республики Мордовия»// «Известия Мордовии», № 54, 25.03.1998, «Ведомости ГС РМ», 1998, № 20-22, ст. 850 .

20 Закон Республики Алтай от 10.11.2008 №101-Р3 «Об административно-территориальном устройстве Республики Алтай» // Приложение к газете «Звезда Алтая», 14.11.2008, «Сборник законодательства Республики Алтай», № 54 (60), октябрь, 2008, с. 3.
} 
преобразования, упразднения, наименования и переименования, установления и изменения границ (черты) административно-территориальных единиц, входящих в их состав населенных пунктов, установления и перенесения административных центров, а также по другим вопросам административно-территориального устройства, а также организуют изучение мнения населения по вопросам образования, объединения, разъединения, преобразования, упразднения, наименования и переименования, установления и изменения границ (черты) административно-территориальных единиц, входящих в их состав населенных пунктов, установления и перенесения административных центров, а также по другим вопросам административнотерриториального устройства ${ }^{21}$.

В Законе Республики Бурятия выделена отдельная глава 4 «Учет мнения населения при решении вопросов административно-территориального устройства Республики» ${ }^{22}$.

Таким образом, ряд субъектов Федерации законодательно закрепляют обязательность определенных демократических процедур учета мнения населения по вопросам административно-территориального устройства, однако, в иных субъектах Федерации эти процедуры законом не предусмотрены или только упоминаются без необходимого подробного регулирования. Накопленный в субъектах Федерации опыт правового регулирования различных форм непосредственной демократии при решении всех вопросов административно-территориального устройства необходимо распространить во всех субъектах Федерации.

В связи с этим представляется актуальным расширение регламентации в законах субъектов Российской Федерации об административно-территориальном устройстве процедур учета мнения населения при изменении административно-территориального устройства. В частности, необходимо шире использовать рекомендательные, консультативные формы выявления мнения населения, такие как опрос, публичные слушания, конференции, собрания.

Предлагаемые шаги обусловлены тем, что одной из важнейших проблем развивающейся российской государственности является преодоление отчуждения гражданина от государства.Политические права и свободы граждан «правомерно рассматривать как обе-

21 Закон Республики Дагестан от 10.04.2002 №16 (ред. от 04.04.2006) «Об административно-территориальном устройстве Республики Дагестан» (принят Народным Собранием РД 28.03.2002) // «Дагестанская правда», № 81, 12.04.2002, «Собрание законодательства Республики Дагестан», 30.04.2002, № 4, ст. 211

22 Закон Республики Бурятия от 10.09.2007 №2433-ІІІ (ред. от 04.05.2008) «Об административно-территориальном устройстве Республики Бурятия» // «Собрание законодательства Республики Бурятия», № 8-9 (101-102), 2007. спеченную человеку законом и публичной властью возможность участия (как индивидуально, так и коллективно) в общественно-политической жизни государства и осуществлении государственной власти» ${ }^{23}$. Согласно ч. 4. ст. 15 Конституции Российской Федерации «общепризнанные принципы и нормы международного права и международные договоры Российской Федерации являются составной частью ее правовой системы».В ст. 21 Всеобщей декларации прав человека ${ }^{24}$ и в ст. 25 Международного пакта о гражданских и политических правах $^{25}$ содержится положение о том, что каждый гражданин без какой бы то ни было дискриминации и без необоснованных ограничений должен иметь право принимать участие в ведении государственных дел как непосредственно, так и через посредство свободно выбранных представителей. В соответствии с этими положениями Конституция Российской Федерации в ч. 1 ст. 32 устанавливает, что «граждане Российской Федерации имеют право участвовать в управлении делами государства как непосредственно, так и через своих представителей». Юридически это право обеспечивает включение граждан в сферу принятия и осуществления государственных решений, в том числе и по вопросам административно-территориального устройства.

В итоге необходимо подчеркнуть недопустимость смешения таких объектов правового регулирования как административно-территориальное устройство субъекта Российской Федерации и территориальная организация местного самоуправления, поскольку они регулируются разными законодательными актами и отличаются по своей природе. Законы субъектов Российской Федерации об административно-территориальном устройстве в части регулирования норм учета мнения населения недостаточно унифицированы, а многие из них непроработаны и в содержательном отношении, и с точки зрения юридической техники. Именно это актуализирует включение федерального законодателя в процесс правового регулирования административно-территориального устройства субъектов Федерации, что однако не снимает необходимости более четкой и подробной регламентации учета мнения населения при изменении административно-территориального устройства субъекта Российской Федерации в региональном законодательстве.

\footnotetext{
${ }^{23}$ Права человека. / Ответственный редактор член-корр. РАН, доктор юридических наук Е.А. Лукашева. М.: Издательство НОРМА. M., 2001. C. 151.

${ }^{24}$ Всеобщая декларация прав человека (принята Генеральной Ассамблеей ООН 10.12.1948) // Российская газета, № 67, 05.04.1995.

${ }^{25}$ Международный Пакт от 16.12.1966 «О гражданских и политических правах» // Бюллетень Верховного Суда Российской Федерации, № 12, 1994.
} 
DOI: $10.7256 / 1811-9018.2013 .8 .9292$

При цитировании этой статьи сноска на dоі обязательна

Право и политика $8(164) \cdot 2013$

Библиография:

1. Авакьян С.А. Институты непосредственной демократии / Конституционные и законодательные основы местного самоуправления в России. М., 2004.

2. Бондарь Н.С. Местное самоуправление и конституционное правосудие: конституционализация муниципальной демократии в России. М.: НОРМА, 2009.

3. Дементьев, А.Н. Правовые гарантии учета мнения населения при изменении границ муниципальных образований // Государственная власть и местное самоуправление. 2005. № 10.

4. Комарова В.В. Референдум и сходные формы непосредственного народовластия (соотношение и проблемы) // Конституционное и муниципальное право. 2005. № 9.

5. Ю.А. Тихомиров. Комментарий к Федеральному закону «Об общих принципах организации местного самоуправления в Российской Федерации». - М., 1997.

6. Краснов М.А. К разработке проекта закона о местном самоуправлении и местном хозяйстве // Сов. государство и право. 1989. № 2.

7. Е.А. Лукашева. Права человека. М.: Издательство HOPМА. М., 2001.

8. Добрынин Н.М., Глигич-Золотарева М.В. Управление развитием федерации: прикладной системный анализ в сфере государственно-территориального устройства. Часть 4. Алгоритм решения системных проблем федерализма // Право и политика. 2011. №

\section{References (transliteration):}

1. Avak'yan S.A. Instituty neposredstvennoy demokratii / Konstitucionnye i zakonodatel'nye osnovy mestnogo samoupravleniya v Rossii. M., 2004.

2. Bondar' N.S. Mestnoe samoupravlenie i konstitucionnoe pravosudie: konstitucionalizaciya municipal'noy demokratii v Rossii. M.: NORMA, 2009.

3. Dement'ev, A.N. Pravovye garantii ucheta mneniya naseleniya pri izmenenii granic municipal'nyh obrazovaniy // Gosudarstvennaya vlast' i mestnoe samoupravlenie. 2005. № 10 .

4. Komarova V.V. Referendum i shodnye formy neposredstvennogo narodovlastiya (sootnoshenie i problemy) // Konstitucionnoe i municipal'noe pravo. 2005. № 9.

5. Yu.A. Tihomirov. Kommentariy k Federal'nomu zakonu «Ob obschih principah organizacii mestnogo samoupravleniya v Rossiyskoy Federacii». - M., 1997.

6. Krasnov M.A. K razrabotke proekta zakona o mestnom samoupravlenii i mestnom hozyaystve // Sov. gosudarstvo i pravo. 1989. № 2.

7. E.A. Lukasheva. Prava cheloveka. M.: Izdatel'stvo NORMA. M., 2001

8. Dobrynin N.M., Gligich-Zolotareva M.V. Upravlenie razvitiem federacii: prikladnoy sistemnyy analiz v sfere gosudarstvenno-territorial'nogo ustroystva. Chast' 4. Algoritm resheniya sistemnyh problem federalizma // Pravo i politika. 2011. № 